\title{
Biodiversity in agricultural landscapes: different non-crop habitats increase diversity of ground-dwelling beetles (Coleoptera) but support different communities
}

\author{
Tamara Rischen $^{1}$ (D) $\cdot$ Tobias Frenzel $^{1} \cdot$ Klaus Fischer $^{1}$
}

Received: 5 February 2021 / Revised: 20 August 2021 / Accepted: 25 August 2021 /

Published online: 1 September 2021

(c) The Author(s) 2021

\begin{abstract}
Agricultural intensification poses a major threat to the conservation of biodiversity and associated ecosystem services. Since non-crop habitats are regarded as important refuges for farmland biodiversity, various greening measures have been proposed to halt biodiversity loss. However, the effectiveness of these measures for biodiversity conservation is still under debate. Therefore, we here compared ground-dwelling beetle (Coleoptera) assemblages of different non-crop habitats (field margins, set-aside fields sown with wildflowers, and permanent grassland fallows) and wheat fields within an intensively used agricultural landscape in western Germany. Taxonomic diversity of Carabidae, Staphylinidae and other coleopteran families and their conservation value were higher in all non-crop habitats than on wheat fields. Surprisingly, though, different types of non-crop habitats did not differ in species richness or the number of threatened species. Thus, field margins and sown wildflower fields were as effective in promoting beetle diversity as grassland fallows. However, different non-crop habitats supported different species assemblages, and several species, in particular especially large ones, were restricted to grassland fallows. These results suggest that different greening measures are effective in promoting the biodiversity of beetles, and that permanent grassland fallows are essential for nature conservation. The fact that habitat types harbored different assemblages stresses the need to combine a variety of greening measures to yield the highest benefit for biodiversity.
\end{abstract}

Keywords Agricultural intensification · Carabidae · Non-crop habitats · Staphylinidae · Synergistic effects

Communicated by Andreas Schuldt.

Tamara Rischen

tamararischen@uni-koblenz.de

1 Department Biology, Institute of Integrated Natural Sciences, Koblenz-Landau University, Universitätsstraße 1, D-56070 Koblenz, Germany 


\section{Introduction}

Due to the growing demand of the human population for agricultural products, farmland management has intensified considerably in recent decades, resulting in a simplification of agricultural landscapes (Tscharntke et al. 2012). Agricultural intensification includes an increasing use of agrochemicals and resources, the conversion of semi-natural habitats into arable land, and the dominance of few crop species on ever larger fields (Benton et al. 2003; Tscharntke et al. 2012). These developments lead to a loss of habitats that are important for the conservation of biodiversity in arable land (Fahrig et al. 2011). Consequently, agricultural intensification poses a major threat to the conservation of biodiversity and associated ecosystem services (Benton et al. 2003). While biodiversity is under pressure at a global scale, farmland species have suffered particularly strong declines over recent decades (Seibold et al. 2019).

Since arable fields are highly disturbed, unstable and short-lived habitats, they are unsuitable for many species (Schneider et al. 2016). Landscape heterogeneity, reflected by the diversity of habitat types, is an important determinant of biodiversity in agricultural landscapes (Fahrig et al. 2011). Non-crop habitats may connect isolated patches of natural vegetation and thus contribute to a heterogeneous environment in agricultural landscapes (Kovács-Hostyánszki et al. 2011). They may comprise important biodiversity reservoirs, as they provide refuges for species not able to survive in crop fields themselves or which have to migrate for overwintering (Tscharntke et al. 2005). The importance of non-crop habitats in agricultural landscapes has already been established for several arthropod taxa (e.g. Clough et al. 2005).

Arthropods are important elements of agroecosystems, as they may contribute, amongst others, to pollination and pest control (Tscharntke et al. 2005). For example, generalist predators such as Carabidae and Staphylinidae (Coleoptera) may reduce aphid densities in winter wheat (Collins et al. 2002). However, the occurrence of beneficial arthropods is strongly related to landscape structure and composition, as is known for Carabidae (Knapp and Řezáč 2015). The habitat selection of these beetles can also be influenced by morphological characteristics. In particular, it has been shown that large carabids tend to avoid disturbed habitats (Cole et al. 2002), presumably because of their limited dispersal ability. Thus, differences in body size and mobility may lead to differences in habitat use (Rainio and Niemela 2003), and body size may consequently serve as an indicator of habitat quality (Eyre et al. 2013). While many carabids have limited dispersal ability, flight-capable rove beetles (Staphylinidae) may colonize arable fields quickly after having overwintered in semi-natural habitats (Thomas et al. 1991). Nevertheless, they show a preference for non-crop habitats, such as grassy field margins, in agricultural landscapes (Pfiffner and Luka 2000). Both beetle families are considered to be important indicators of changes in management practices in agricultural landscapes (Bohac 1999; Kromp 1999).

To protect and restore biodiversity in agricultural landscapes, European agri-environmental schemes, funded under the Common Agricultural Policy (CAP), aim at creating and maintaining non-crop habitats (Holland et al. 2017). While some agri-environmental schemes are considered successful (Perkins et al. 2011), the benefits of others have been widely discussed (Kleijn et al. 2011). So called greening measures were introduced with the last CAP reform to reduce the negative impact of agriculture on the environment and to counteract the loss of biological diversity (Birkhofer et al. 2018; Boetzl et al. 2021). There is broad agreement that remnants of (semi-)natural vegetation and long-term fallows comprise important conservation areas for arthropods in agricultural landscapes (Geiger 
et al. 2009; Holland et al. 2017), but the effectiveness of grassy field margins versus shortterm set-aside, wild-flower-sown fields is rather unclear. Grassy field margins comprise relatively stable habitats, but their small width and close proximity to arable fields make them susceptible to, for example, drifting pesticides (Longley et al. 1997). Set-aside fields are more unstable habitats, typically available for a few years only (Van Buskirk and Willi 2004), thus strongly depending on immigration. In summary, both greening measures may be considerably less valuable compared to permanent fallows. However, it is currently largely unclear whether one or the other is more effective in promoting biodiversity in agricultural landscapes, as only few studies have compared grassy field margins with sown wildflower fields (e.g. Meek et al. 2002). Such data are necessary though for evidencedbased conservation recommendations.

Against this background, we here set out to compare ground-dwelling beetle diversity across different habitat types permanent grassland fallows, grassy field margins, set-aside sown wildflower fields, and crop fields) within an intensively used agricultural landscape in western Germany. Specifically, we set out to evaluate the effectiveness of permanent fallows, grassy field margins, and sown wildflower fields, comprising widespread conservation measures for promoting biodiversity. We include Staphylinidae and other beetle families in addition to Carabidae to test the following hypotheses: (1) Permanent grassland fallows with their large patch sizes and relatively stable conditions hold the highest and crop fields the lowest beetle diversity. (2) Grassy field margins and sown wildflower fields show intermediate levels of diversity (i.e. in between the above two) due to the less favorable conditions compared to permanent fallows but do not differ among each other. (3) Community mean body size is on average smaller on wheat fields as compared with semi-natural habitats, since large beetles can be negatively affected by disturbance (Blake et al. 1994). We do not expect specific differences among Carabidae, Staphylinidae and the remaining beetle families, but use different taxonomic groups to explore the consistency of patterns.

\section{Materials and methods}

\section{Study area}

The study area ('Maifeld'), an intensively used agricultural landscape, is located in the Eifel mountain range in western Germany $\left(50^{\circ} 14^{\prime} \mathrm{N}, 7^{\circ} 21^{\prime} \mathrm{E}\right.$; Fig. 1). The region is characterized by an oceanic climate, with an average annual precipitation of $\sim 598 \mathrm{~mm}$ and an average annual temperature of $\sim 10{ }^{\circ} \mathrm{C}$ (Agrarmeteorologie Rheinland-Pfalz 2020). The landscape is dominated by crop fields, with occasional non-crop habitats such as meadows, permanent grassland fallows or field margins. In 2018, 72.2\% of the Maifeld consisted of agricultural land, while only $11.8 \%$ was covered with forests and $13.9 \%$ with settlement and traffic areas (Statistisches Landesamt Rheinland-Pfalz 2018). To assess the impact of land use on beetle assemblages, we compared five habitat types using 10 replicate plots for each (Fig. 1; Table A1, Supplementary Material): (1) wheat fields sown with Triticum aestivum (conventional management with fertilizing, fungicide and herbicide spraying), (2) grassy field margins bordering oilseed rape fields (mown once during sampling), (3) grassy field margins bordering wheat fields (mown once during sampling), (4) set-aside sown wildflower fields (1-2 years old fallows, sown with a mixture of wildflower seeds as 'greening' measure; hereafter 'sown wildflower fields'), (5) grassland fallows (unmanaged, 

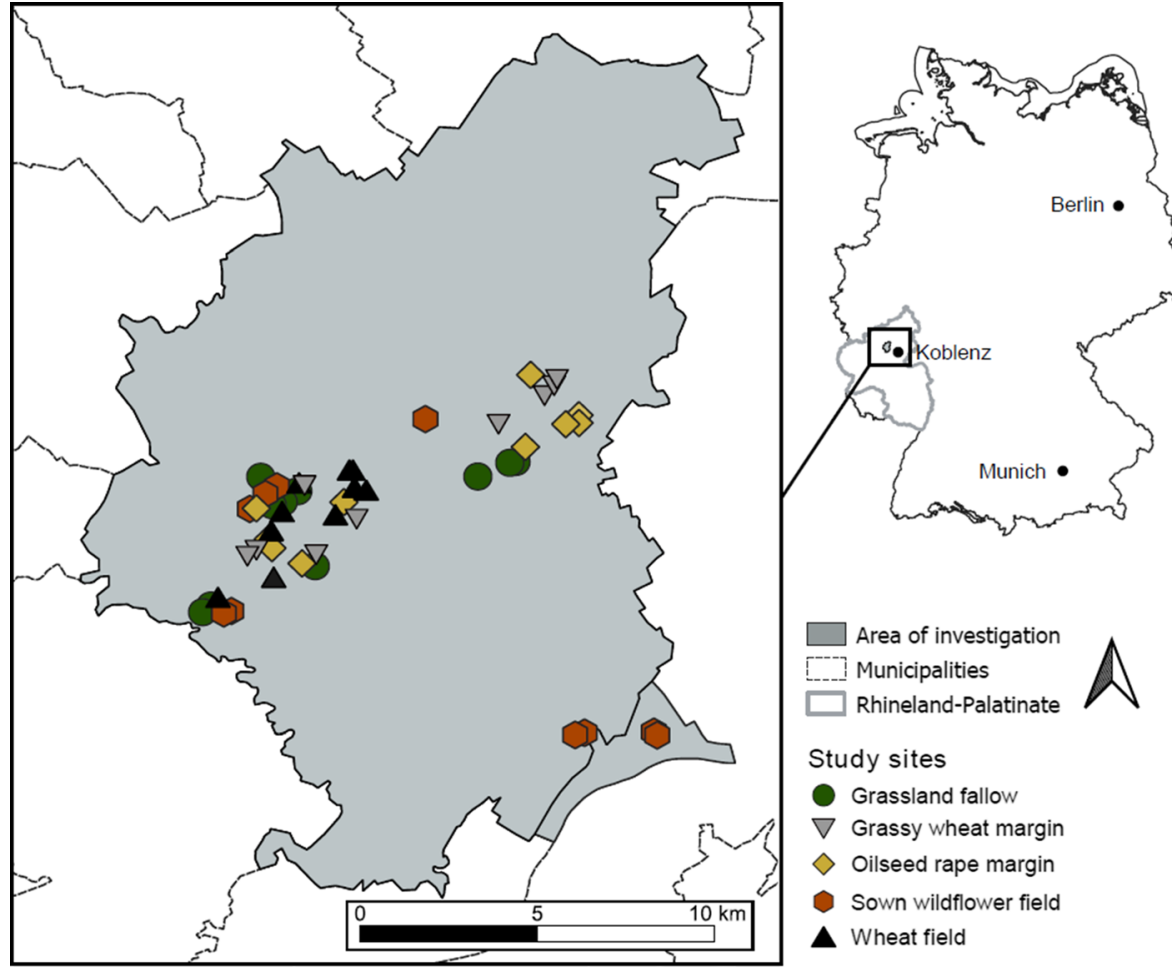

Fig. 1 Location of the study area near the city of Koblenz within Germany and of the study sites (enlarged) within the 'Maifeld'. The map was generated using QGIS version 3.14 (www.qgis.org)

permanent fallows with a diverse semi-natural vegetation cover, formerly used as meadows but abandoned decades ago).

\section{Field methods and data analyses}

From 23rd May to 3rd July 2019, beetles were sampled by pitfall trapping during four time periods of approximately 12 days each using PET cups $(\varnothing=5.6 \mathrm{~cm}$, volume $125 \mathrm{ml}$, filled with $70 \%$ water and $30 \%$ monopropylene glycol). The number of trapping days per site ranged between 41 and 42 days. Per site, three pitfall traps, covered with a plastic roof for protection, were buried into the ground at distances of ten meters in a straight line. All pitfall traps were placed into the respective plots with a minimum distance of $20 \mathrm{~m}$ from the nearest edge, except for field margins. Collected beetles were preserved in $70 \%$ ethanol until species identification using taxonomic keys (Freude et al. 1964-83). Critical taxa were determined via genital preparation or only to the morpho-species level ( 5 species in total). Morpho-species were used in the genera Aleochara (2 species, 1741 individuals), Staphylinidae; Atheta (1, 7), Staphylinidae; Atomaria (2, 633), Cryptophagidae. The data of the three traps per site were pooled over the entire sampling period for subsequent analyses.

As different beetle families may differ in ecology including habitat requirements (Lange et al. 2014), we decided to analyze the two most abundant families, Carabidae and Staphylinidae, separately. Therefore, our data were analyzed according to the following groups: (1) 
all beetle families / species found, (2) all Carabidae, (3) all Staphylinidae, and (4) all species from the remaining families (i.e. excluding Carabidae and Staphylinidae). We compiled the numbers of species, individuals, threatened species, and individuals of threatened species (according to Geiser 1998) per plot. We estimated the effective number of species, a derivative of the Shannon-Wiener-index representing the actual diversity (Jost 2006). In addition, we calculated the 'conservation value' according to Görn and Fischer (2011) by assigning each species a point score according to its German red list status (Geiser 1998): not threatened $=1$ point, near threatened $(\mathrm{V})=5$ points, vulnerable $(3)=10$, endangered $(2)=20$. The conservation value represents the sum of all species-specific point scores for all species present at a plot. Moreover, the body size of each species was determined by using data available in Freude et al. (1964-83) and Homburg et al. (2014; for carabid beetles). Community weighted mean (CWM) values for body sizes were calculated by weighting the respective body size by each species' abundance (Ricotta and Moretti 2011).

Based on Freude et al. (1964-83) and Homburg et al. (2014), all carabids, staphylinids and all other species were classified according to their food preferences as zoophagous, phytophagous, or other). Other diets included omnivorous, mycetophagous, and saprophagous species, which occurred only in low numbers. While the staphylinds are almost exclusively zoophagous, nearly $40 \%$ of all species in the remaining families belong to the phytophagous Chrysomelidae and Curculionidae. Furthermore, all carabids and staphylinids were assigned according to their habitat preferences (o: open landscape species, e: eurytopic species, h: hygrophilic species). Homburg et al. (2014) was also used to classify all carabids according to their flight ability as good (winged) or poor (wingless and dimorphic species). For subsequent analyses, we standardized the above data by giving the respective proportion per plot. Furthermore, for species with $\geq 100$ individuals, the preference for a certain habitat type was determined if more than $50 \%$ of all individuals were found in a specific habitat type. In addition, we determined the size, lengths and widths of each investigated plot with the distance tool in GoogleMaps. The perimeter-to-area ratio was calculated to determine the shape of the plots.

\section{Statistical analyses}

To analyze variation in the numbers of species, individuals, threatened species, individuals of threatened species, the effective number of species, conservation value, and CWM body size, we used general linear models (GLMs) with habitat type as fixed effect and sampling day, habitat size and shape as covariates. However, effects of covariates were non-significant throughout, except for a significant effect of habitat shape on CWM body size in staphylinid beetles, which did not affect the effect of habitat type. We therefore removed all covariates from the models and performed one-way ANOVAs with habitat type as fixed effect. Tukey HSD post-hoc tests were used to determine significant differences between habitat types. Note that not all indices were measured in all four taxonomic groups. Specifically, numbers of threatened species and individuals of threatened species as well as conservation value were only analyzed for all species together, as the number of threatened species was too low to perform separate analyses. To achieve normal distribution and homogeneity of variance, the values for (1) the number of individuals for carabid, staphylinid beetles and remaining families, (2) the effective number of species of carabid beetles and remaining families and (3) the CWM body size for staphylinid beetles and remaining families were LN-transformed, and (4) the individuals of threatened species were $\mathrm{LN}+1$-transformed prior to analyses. We tested for spatial autocorrelation of 
dependent variables using Moran's I tests and the function autocov_dist in the 'ape' package (Dormann et al. 2007; Paradis and Schliep 2019). However, significant autocorrelations were not found throughout.

Permutational multivariate analyses of variance (PERMANOVAs, with 999 permutations) were used to test for significant differences between habitat types in the proportion of species with specific food (carabids, staphylinids, and species from the remaining families) and habitat preferences (carabids and staphylinids only) or flight ability (carabids only). For standardization, we used the relative abundance of species throughout. For carabids, staphylinids, remaining families, and all beetles together, community composition among the five habitat types was analyzed using non-metric multidimensional scaling (NMDS), also based on the relative abundance of species (Bray-Curtis distance matrix). Subsequently, PERMANOVAs (999 permutations) were used to test for significant differences between habitat types. Statistical analyses were performed with Statistica 12.0 (Tulsa, StatSoft) or using the vegan package in R 3.4.0 for NMDS and PERMANOVA (R Development Core Team 2017; Oksanen et al. 2020).

\section{Results}

We collected in total 32,414 beetles belonging to 284 species (Table A2, Supplementary Material). The most numerous families were the ground-dwelling beetle families Carabidae and Staphylinidae, which accounted for about $81 \%$ of all individuals. Eight species accounted for $43 \%$ of all individuals: Philonthus cognatus (Staphylinidae; 2439 individuals), Poecilus cupreus (Carabidae; 2321), Anchomenus dorsalis (Carabidae; 2210), Tachyporus hypnorum (Staphylinidae; 1832), Pterostichus melanarius (Carabidae; 1618), Bembidion lampros (Carabidae; 1311), Drusilla canaliculata (Staphylinidae; 1136), and Tachinus signatus (Staphylinidae; 1083). Five species are listed in the Red List of Germany as near threatened, ten as vulnerable, and six species as endangered (Table A2, Supplementary Material). Of the species with $\geq 100$ individuals, three showed a preference for wheat fields and six species for oilseed rape margins (Table 1). Moreover, five species showed a close association with grassy wheat margins and six species to sown wildflower fields. A preference for grassland fallows was found for eight species.

Habitat type significantly influenced (1) the number of species in all taxonomic groups, (2) the number of individuals in Staphylinidae and remaining families, (3) the effective number of species in all beetles together and in the Carabidae, and (4) the CWM body size in all beetles together and in the remaining families (Table 2; Fig. 2). In addition, habitat type significantly affected the number of threatened species, the individuals of threatened species, and conservation value in all beetles (Fig. 3). Typically, wheat fields showed the lowest values, though note that not all differences to non-crop habitats were significant. Non-crop habitats were generally statistically indistinguishable (Figs. 2 and 3).

PERMANOVAs indicated significant differences among habitat types in food preferences, habitat preferences, and flight ability of carabid beetles (food preference: $\mathrm{F}_{4,45}=$ 4.92, $\mathrm{p}=0.001, \mathrm{R}^{2}=0.30$; habitat preference: $\mathrm{F}_{4,45}=2.93, \mathrm{p}=0.009, \mathrm{R}^{2}=0.21$; flight ability: $\mathrm{F}_{4,45}=11.84, \mathrm{p}=0.001, \mathrm{R}^{2}=0.51$ ), in food preferences of all other beetle families $\left(\mathrm{F}_{4,45}=5.98, \mathrm{p}=0.001, \mathrm{R}^{2}=0.35\right)$, and in habitat preferences of staphylinid beetles $\left(\mathrm{F}_{4,45}=3.11, \mathrm{p}=0.014, \mathrm{R}^{2}=0.22\right)$. Regarding food preferences, the proportion of zoophagous carabid species was highest on wheat fields and grassy wheat margins (Fig. 4). For other beetle families, the highest proportion of phytophagous species was 
Table 1 List of species with $\geq 100$ individuals showing a preference for a certain habitat type

\begin{tabular}{|c|c|c|}
\hline Species $\geq 100$ individuals & Family & $\%$ \\
\hline \multicolumn{3}{|l|}{ Wheat field } \\
\hline Dinaraea angustula & Staphylinidae & 61 \\
\hline Anotylus insecatus & Staphylinidae & 56 \\
\hline Loricera pilicornis & Carabidae & 53 \\
\hline \multicolumn{3}{|l|}{ Oilseed rape margin } \\
\hline Tachinus signatus & Staphylinidae & 75 \\
\hline Philonthus decorus & Staphylinidae & 70 \\
\hline Philonthus laminatus & Staphylinidae & 65 \\
\hline Sepedophilus marshami & Staphylinidae & 56 \\
\hline Amara similata & Carabidae & 79 \\
\hline Amara communis & Carabidae & 58 \\
\hline \multicolumn{3}{|l|}{ Grassy wheat margin } \\
\hline Calathus fuscipes & Carabidae & 64 \\
\hline Pterostichus melanarius & Carabidae & 55 \\
\hline Ootypus globosus & Cryptophagidae & 60 \\
\hline Atomaria spec. 2 & Cryptophagidae & 66 \\
\hline Atomaria spec. 1 & Cryptophagidae & 52 \\
\hline \multicolumn{3}{|l|}{ Sown wildflower field } \\
\hline Anthicus antherinus & Anthicidae & 82 \\
\hline Atomaria linearis & Cryptophagidae & 67 \\
\hline Microlestes minutulus & Carabidae & 58 \\
\hline Aleochara spec. 2 & Staphylinidae & 75 \\
\hline Aleochara spec. 1 & Staphylinidae & 52 \\
\hline Phyllotreta atra & Chrysomelidae & 83 \\
\hline Chaetocnema hortensis & Chrysomelidae & 74 \\
\hline \multicolumn{3}{|l|}{ Grassland fallow } \\
\hline Agonum viduum & Carabidae & 100 \\
\hline Carabus granulatus & Carabidae & 100 \\
\hline Anisodactylus binotatus & Carabidae & 96 \\
\hline Pterostichus anthracinus & Carabidae & 96 \\
\hline Poecilus versicolor & Carabidae & 93 \\
\hline Carabus auratus & Carabidae & 60 \\
\hline Amara lunicollis & Carabidae & 54 \\
\hline Onthophagus joannae & Scarabaeidae & 59 \\
\hline
\end{tabular}

The percentage of individuals found in the given habitat type is given in percent

found in sown wildflower fields. Regarding habitat preferences, open landscape species dominated throughout in the Carabidae, but grassland fallows showed a much higher proportion of hygrophilic species than all other habitat types. Staphylinid assemblages showed an increase in the proportion of open landscape and hygrophilic species but a decrease in the proportion of eurytopic species from wheat fields to grassland fallows. Wheat fields were dominated by carabid beetles with good flight ability. Variation 
Table 2 Results of ANOVAs for the effects of habitat type on dependent variables in all beetle families analyzed together, Carabidae, Staphylinidae, and the remaining beetle families

\begin{tabular}{lllllr}
\hline & & DF & MS & F & p \\
\hline All families & Species number & 4,45 & 759 & 5.95 & $\mathbf{0 . 0 0 1}$ \\
& Number of individuals & 4,45 & 235,098 & 2.30 & 0.073 \\
& Effective species number & 4,45 & 92.3 & 3.49 & $\mathbf{0 . 0 1 4}$ \\
& CWM body size & 4,45 & 6.83 & 3.27 & $\mathbf{0 . 0 2 0}$ \\
& Red list species & 4,45 & 5.55 & 2.77 & $\mathbf{0 . 0 3 9}$ \\
Rarabidae & Red list individuals & 4,45 & 2.47 & 2.86 & $\mathbf{0 . 0 3 4}$ \\
& Conservation value & 4,45 & 2777 & 5.04 & $\mathbf{0 . 0 0 2}$ \\
& Species number & 4,45 & 67.6 & 2.73 & $\mathbf{0 . 0 4 1}$ \\
& Number of individuals & 4,45 & 0.30 & 0.63 & 0.642 \\
Staphylinidae & Effective species number & 4,45 & 0.29 & 2.78 & $\mathbf{0 . 0 3 8}$ \\
& CWM body size & 4,45 & 4.31 & 1.33 & 0.272 \\
& Species number & 4,45 & 93.3 & 3.83 & $\mathbf{0 . 0 0 9}$ \\
& Number of individuals & 4,45 & 1.84 & 3.53 & $\mathbf{0 . 0 1 4}$ \\
& Effective species number & 4,45 & 21.08 & 2.41 & 0.063 \\
& CWM body size & 4,45 & 0.09 & 1.79 & 0.148 \\
& Species number & 4,45 & 157.3 & 5.84 & $\mathbf{0 . 0 0 1}$ \\
& Number of individuals & 4,45 & 3.52 & 9.03 & $<\mathbf{0 . 0 0 1}$ \\
& Effective species number & 4,45 & 0.08 & 0.64 & 0.639 \\
& CWM body size & 4,45 & 0.49 & 3.37 & $\mathbf{0 . 0 1 7}$ \\
\hline
\end{tabular}

Significant p-values are given in bold. $C W M$ community weighted mean

in food preferences were not significant for staphylinid beetles, as zoophagous species dominated in all habitat types $\left(\mathrm{F}_{4,45}=0.85, \mathrm{p}=0.541, \mathrm{R}^{2}=0.07\right)$.

The NMDS ordinations demonstrated strong variation in species assemblages among habitat types for all taxonomic groups (PERMANOVAs; Carabidae: $\mathrm{F}_{4,45}=4.51, \mathrm{p}=0.001$, $\mathrm{R}^{2}=0.29$; Staphylinidae: $\mathrm{F}_{4,45}=5, \mathrm{p}=0.001, \mathrm{R}^{2}=0.31$; remaining families: $\mathrm{F}_{4,45}=5.15$, $\mathrm{p}=0.001, \mathrm{R}^{2}=0.31$; all beetles: $\mathrm{F}_{4,45}=4.87, \mathrm{p}=0.001, \mathrm{R}^{2}=0.30$ ). Throughout, withingroup variation of beetle assemblages was much higher for grassland fallows than for any other group (Fig. 5). For carabid beetles, there was a clear separation of the assemblages of wheat fields / margins, oilseed rape margins, and sown wildflower fields, while grassland fallows overlapped with all other habitat types. In staphylinid beetles and all beetles, wheat fields differed strongly from all other habitat types. The remaining families, finally, showed clearly different assemblages for all habitat types except from grassy wheat and oilseed rape margins.

\section{Discussion}

Our results support the notion that non-crop habitats are valuable for ground-dwelling beetles in intensively used agricultural landscapes (e.g. Meek et al. 2002), as evidenced by a higher species richness in non-crop habitats than in wheat fields for Carabidae, Staphylinidae, and remaining beetle families. Similar patterns were found for the numbers of species and individuals of threatened species and concomitantly conservation value, where 

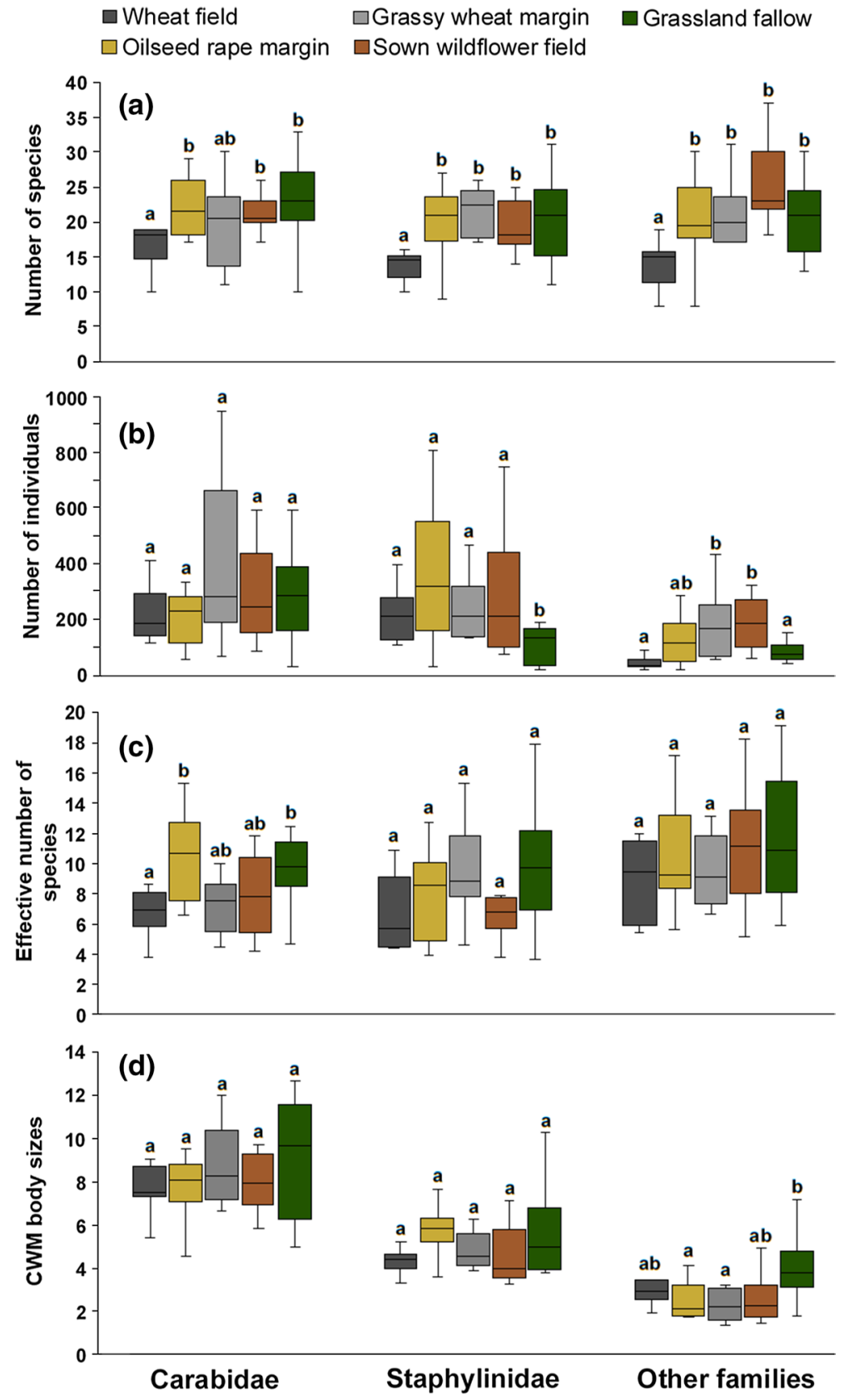

Fig. 2 Number of species a, number of individuals b, effective number of species $\mathbf{c}$, and CWM body size d for Carabidae, Staphylinidae and other families across five habitat types. Boxplots display the interquartile range (25-75\%; box) and the median (line in the box). Whiskers represent 1.5 of the lower or upper interquartile range. Different letters above bars indicate significant differences among treatments (Tukey HSD after ANOVA) 
Fig. 3 Conservation values a, number of threatened species b, and number of threatened individuals $\mathbf{c}$ for all beetles combined across habitat types. Boxplots display the interquartile range (25-75\%; box) and the median (line in the box). Whiskers represent 1.5 of the lower or upper interquartile range. Different letters above bars indicate significant differences among treatments (Tukey HSD after ANOVAs) $\square$ Wheat field

$\square$ Oilseed rape margin

$\square$ Grassy wheat margin

$\square$ Sown wildflower field

$\square$ Grassland fallow
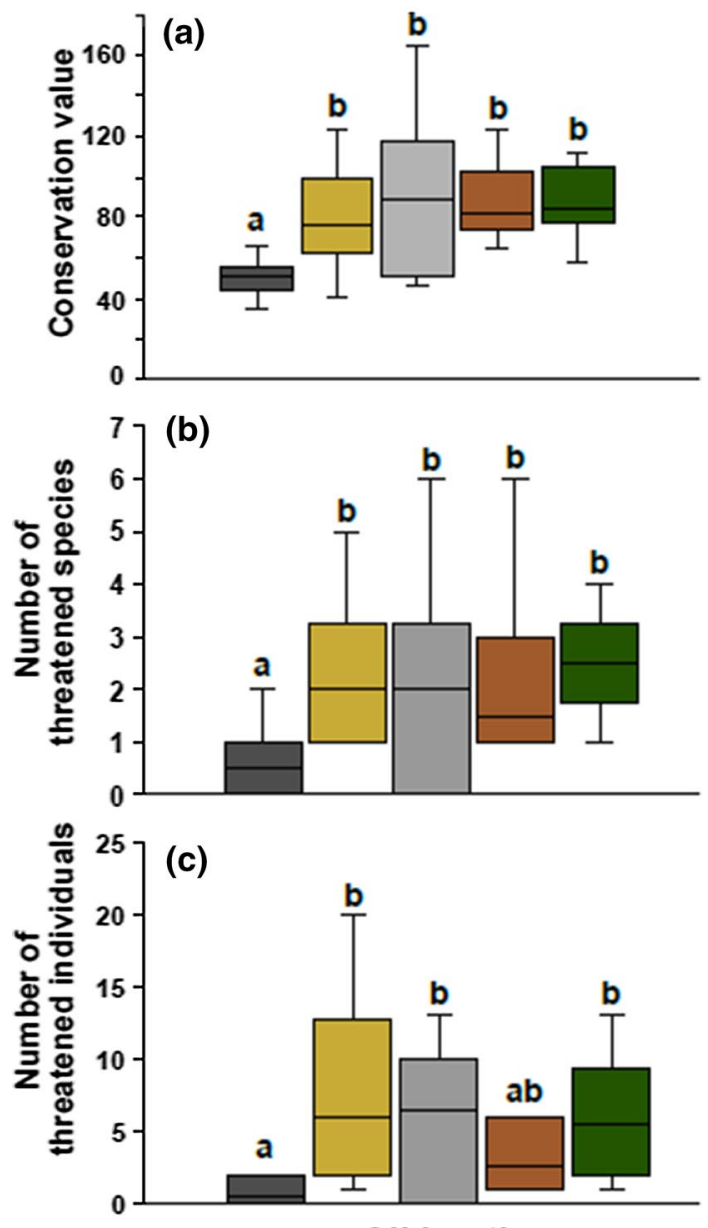

All beetles

permanent grassland fallows consistently showed the highest values. Thus, while a low biodiversity of wheat fields is clearly demonstrated by our data, it is remarkable that non-crop habitats did not differ significantly in any of the above indices. Beetle diversity was, as predicted, higher on grassland fallows than on wheat fields, but grassy field margins and sown wildflower fields were partly equally effective in promoting biodiversity. This is despite the fact that field margins were very narrow, such that edge and spillover effects seemed likely. However, such effects may not necessarily be negative, they may even increase species richness and activity density (Schneider et al. 2016). Similarly, sown wildflower fields do not seem to suffer substantially from their former use as crops fields. This may be related to the typically high spatio-temporal dynamics of beetle assemblages in agricultural landscapes. Beetles may respond rapidly, for instance, to crop rotations (Marrec et al. 


\section{Carabidae}

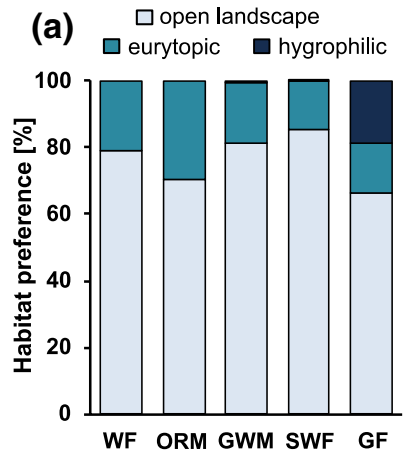

$\square$ phytophagous
$\square$ other diets $\square$ zoophagous

(c) $\square$ poor $\square$ good
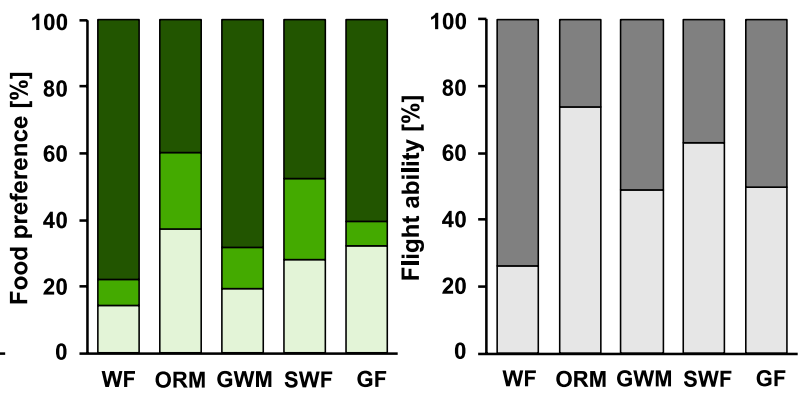

\section{Staphylinidae}
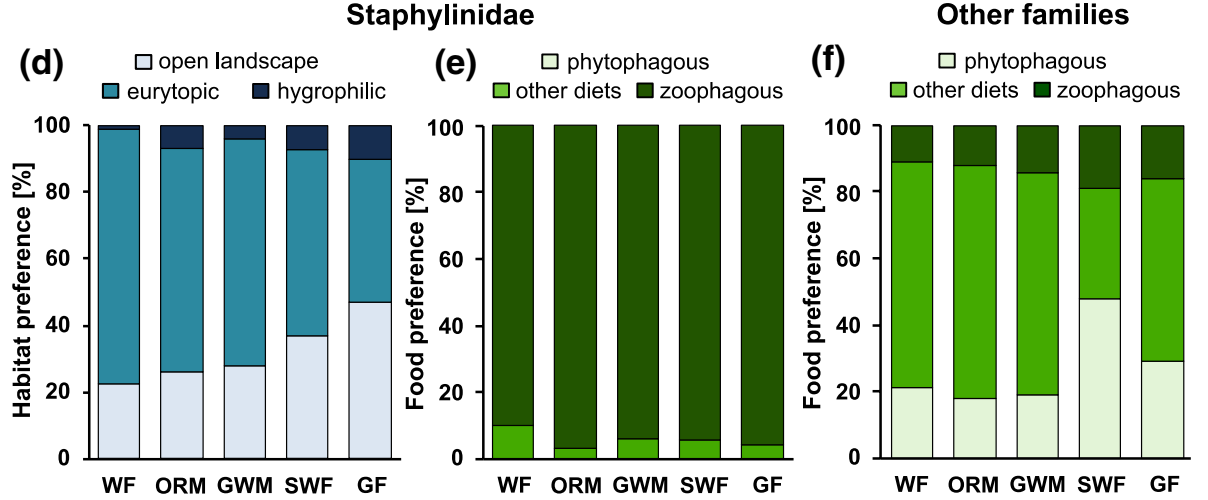

Fig. 4 Distributions of habitat preferences $\mathbf{a}$, food preferences $\mathbf{b}$, and flight ability $\mathbf{c}$ for Carabidae, habitat $\mathbf{d}$ and food preferences e for Staphylinidae, and food preferences for the other families $\mathbf{f}$ in wheat fields (WF), oilseed rape margins (ORM), grassy wheat margins (GWM), sown wildflower fields (SWF), and grassland fallows (GF). Data according to Freude et al. (1964-83) and Homburg et al. (2014)

2017). Thus, beetles were probably attracted to sown wildflower fields by the diversity of wildflowers and other resources. This is further supported by the high species richness and activity-density of the remaining beetle families on the sown wildflower fields (Fig. 2a), including many species of Curculionidae and Chrysomelidae being often related to plant species richness (e.g. Frank et al. 2012). Carabid and staphylinid beetles are often attracted to older wildflower areas (Frank and Reichhart 2004), such that the period since setting aside an area may be an important factor. Overall, many beetle species found in non-crop habitats were completely absent from wheat fields, as also found in other studies (Knapp and Řezáč 2015). This is presumably caused by the ephemeral nature of wheat fields due to frequent disturbance (Kosewska et al. 2014). Accordingly, non-crop habitats can be crucial for the survival of various animal taxa that are unlikely to survive in arable fields (Knapp and Řezáč 2015). For instance, non-crop habitats are used by beetles for breeding, as shelter, stepping stones for dispersal (Holland and Luff 2000) or as hibernation sites (Geiger et al. 2009).

Beetle assemblages differed strongly among habitat types, being most pronounced in the remaining families and least pronounced in the Carabidae. Assemblages of wheat fields were remarkably homogeneous throughout, while those of grassland fallows 


\section{- Grassland fallow $\nabla$ Grassy wheat margin $\diamond$ Oilseed rape margin}

\section{Sown wildflower field \\ Wheat field}
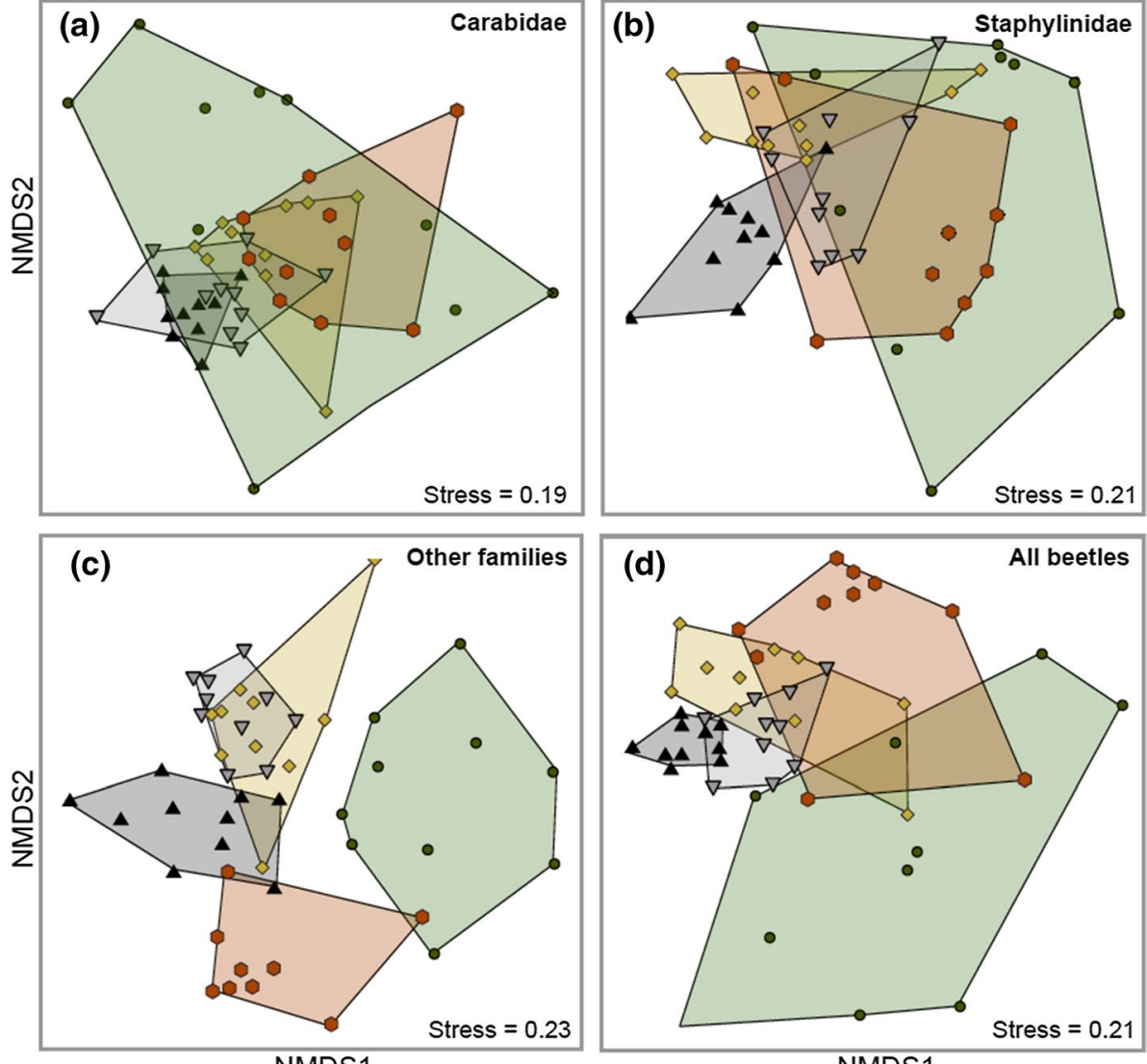

Fig. 5 Non-metric multidimensional scaling analysis (NMDS) for beetle assemblages of Carabidae (a based on 79 species and 14,055 individuals), Staphylinidae (b based on 79 species and 12,154 individuals), all remaining beetle families (c based on 124 species and 6205 individuals), and all beetles combined (d based on 184 species and 32,414 individuals) across five habitat types ( $\mathrm{n}=50$ plots, 2 dimensions, Bray-Curtis distance)

showed the largest within-group variation. Overall, wheat fields, grassy field margins, sown wildflower fields and grassland fallows harbored strikingly different beetle assemblages. In addition, all non-crop habitats also provided suitable habitats for various threatened species, which is reflected in the high conservation values compared to wheat fields. Thus, all conservation measures investigated here promote beetle diversity in different ways and complement each other. Improving local beetle diversity through the availability of different non-crop habitats in agroecosystems underlines the importance of landscape composition and configuration for the conservation of farmland biodiversity (Martin et al. 2019). For beetles, habitat type (vegetation; Weibull and Östman 2003), size and spatial configuration of landscape elements (Duflot et al. 2017) are important factors explaining variation in local assemblages. Although Carabidae 
were hitherto mainly investigated in agroecosystems (e.g. Kosewska et al. 2014), the Staphylinidae were similarly abundant in our study. On farmland, the abundance of staphylinid beetles may even be higher than that of Carabidae (Bohac 1999), possibly due to their higher flight ability and thus dispersal rates (Lange et al. 2014). Due to difficulties in species identification, knowledge on staphylinid beetles is often limited, but this understudied group may serve as important bioindicators (Hoffmann et al. 2016).

The high variation in the assemblages of Carabidae, Staphylinidae and the remaining beetle families on grassland fallows likely results from a more diverse habitat structure, including variation in soil moisture (partly high), different coverages of herbs, and sometimes a few trees and shrubs. This is also mirrored by the habitat and food preferences of the Carabidae and Staphylinidae. While in wheat fields almost exclusively open landscape and eurytopic individuals occurred, grassland fallows additionally hosted substantial numbers of hygrophilic individuals (Fig. 4). Likewise, the number of phytophagous individuals of the Carabidae was higher in all non-crop habitats than in wheat fields, probably reflecting increased vegetation cover (grasses and herbs) relevant for food supply (Schirmel et al. 2016). Compared to the predatory carabid beetles, phytophagous species are probably more specialized and dependent on the local habitat type (Woodcock et al. 2010). The high proportion of phytophagous individuals found in sown wildflower fields in the remaining beetle families may be related to the seed mixtures that favour the establishment of plant species preferred by many phytophagous species (Marshall and Moonen 2002). In addition, some pest species such as Chaetocnema hortensis (Chrysomelidae) and Sitona lineatus (Curculionidae) (Lethmayer et al. 1997) were found in wildflower fields. Especially the cereal pest species $C$. hortensis occurred in high activity densities, which may be related to the former use as cropland or the absence of pesticide use. However, the presence of some threatened species in the sown wildflower fields that were absent in wheat fields indicates the importance of these areas. In contrast to simplified monocultures, wildflower fields with a high structural and botanical diversity, including perennial plant species, can be very attractive for many arthropods in agricultural landscapes (Haaland et al. 2011).

In contrast, wheat fields were clearly dominated by zoophagous individuals, probably due to the high availability of prey such as aphids. Thus, predatory beetle species may contribute to biological pest control (Dennis and Wratten 1991). This may also explain the lack of significant differences in activity-density between land use types (Fig. 2b), although higher activity densities in beetles have been recorded in non-crop habitats (e.g. Knapp and Řezáč 2015). Still, some predaceous species may thrive on wheat fields showing high activity densities (e.g. Tachyporus hypnorum and Anchomenus dorsalis). In addition, frequent movement of ground-dwelling carabid and staphylinid beetles between wheat fields and adjacent habitats may cause higher activity-densities in field margins (Birkhofer et al. 2018). We can also not rule out biases due to our sampling method, since the results of pitfall trapping may depend on both vegetation structure and the activity of invertebrates (Thomas et al. 2006). It is conceivable that the higher vegetation density in non-crop habitats compared with wheat fields reduced activity levels and thus the catch. Possibly, the use of multiple sampling methods would have been more effective to assess activity-density (Gobbi et al. 2018). Finally, Sirami et al. (2019) and others point to the importance of landscape-level effects on the decline of biodiversity in agricultural landscapes. Given that such effects are strong, they will reduce any differences among habitat types within a given landscape. This may further apply to species numbers, and may explain the lack of variation among non-crop habitats. Perhaps, beetle assemblages are impoverished even in seminatural sites within our study area with its long history of intensive agriculture. 
Our results do not show a general decrease in mean community body size with increasing agricultural disturbance, unlike some other studies (see Kosewska et al. 2014). In particular large ground beetles tend to avoid disturbed and to prefer undisturbed habitats (Cole et al. 2002). They often have limited dispersal ability and therefore take longer to colonize habitats. This is also reflected in our results on flight ability, where carabids with poor flight ability dominated in all non-crop habitats (Fig. 4c). However, decreased body size on wheat fields could only be found in the remaining beetle families, but not in Carabidae and Staphylinidae. In our study, we found higher activity-densities of large carnivorous ground beetles, such as Pterostichus melanarius, in wheat fields and grassy wheat margins, possibly due to the availability of prey in the productive crop fields (Collins et al. 2002) or because they can benefit from increasing management intensity (Winqvist et al. 2014). However, we did find that large ground beetle species $(>10 \mathrm{~mm})$ such as Carabus granulatus, Anisodactylus binotatus, and Carabus auratus preferred grassland fallows (100\% for C. granulatus). In addition, some species, e.g. A. binotatus and C. auratus, were also found in other non-crop habitats but not in wheat fields. Thus, at least for specific species and taxa, adjacent non-crop habitats may contribute to the conservation of large predatory beetle species in croplands (Hanson et al. 2016).

\section{Conclusions}

As expected, wheat fields represented suboptimal habitats for Carabidae, Staphylinidae and other beetle families, while the nearby non-crop habitats comprised important refuge areas for the beetle fauna. Interestingly, grassy field margins and sown wildflower fields, which had been used as crop fields in the previous year, were as effective in promoting beetle diversity as grassland fallows, most of which have presumably never been used as crop fields. The unexpectedly poor performance of the latter may reflect landscape level effects of agriculture, resulting in an impoverished fauna in these highly isolated habitat fragments surrounded by intensively used crop fields. Nevertheless, our data clearly show that both field margins and sown wildflower fields promote biodiversity in an agricultural landscape, and are thus valuable for restoring biodiversity and ecosystem services. A combination of approaches will likely yield highest benefits, evidenced by variation among the assemblages of different habitat types (see also Boetzl et al. 2021). Nevertheless, permanent fallows are indispensable for conservation, as they comprise refuge areas for different specialists or particularly large species (e.g. several carabids).

Supplementary Information The online version contains supplementary material available at https://doi. org/10.1007/s10531-021-02284-7

Acknowledgements We are grateful to Marco Helms and Roland Busch for support in the field. We thank Jonas Köhler and Thomas Wagner for help with species identifications, and the local farmers and landowners, especially Markus Müller and Johannes Maur, for their support and for allowing us to carry out this study on their properties. We thank two anonymous reviewers for their insightful and constructive criticism.

Authors' contributions KF and TM designed the experiment, TR and TM collected field data, TR identified the beetles, KF analyzed the data with help from TR, TR and KF wrote the manuscript.

Funding Open Access funding enabled and organized by Projekt DEAL. This study was financially supported by the Ministry for Environment, Energy, Nutrition and Forest Rheinland-Pfalz through the 'Aktion Grün'. 
Data availability All data are provided as supplementary material.

\section{Declarations}

Conflicts of interest The authors declare that they have no conflict of interest.

Open Access This article is licensed under a Creative Commons Attribution 4.0 International License, which permits use, sharing, adaptation, distribution and reproduction in any medium or format, as long as you give appropriate credit to the original author(s) and the source, provide a link to the Creative Commons licence, and indicate if changes were made. The images or other third party material in this article are included in the article's Creative Commons licence, unless indicated otherwise in a credit line to the material. If material is not included in the article's Creative Commons licence and your intended use is not permitted by statutory regulation or exceeds the permitted use, you will need to obtain permission directly from the copyright holder. To view a copy of this licence, visit http://creativecommons.org/licenses/by/4.0/.

\section{References}

Agrarmeteorologie Rheinland-Pfalz (2020) Langjährige Mittelwerte der Wetterstation Münstermaifeld. https://www.am.rlp.de. Accessed 10 Sep 2020

Benton TG, Vickery JA, Wilson JD (2003) Farmland biodiversity: is habitat heterogeneity the key? Trends Ecol Evol 18:182-188

Birkhofer K, Fevrier V, Heinrich A et al (2018) The contribution of CAP greening measures to conservation biological control at two spatial scales. Agric Ecosyst Environ 255:84-94. https://doi.org/10.1016/j. agee.2017.12.026

Blake S, Foster GN, Eyre MD, Luff ML (1994) Effects of habitat type and grassland management practices on the body size distribution of carabid beetles. Pedobiologia 38:502-512

Boetzl FA, Krauss J, Heinze J et al (2021) A multitaxa assessment of the effectiveness of agri-environmental schemes for biodiversity management. Proc Natl Acad Sci 118:1-9. https://doi.org/10.1073/pnas. 2016038118

Bohac J (1999) Staphylinid beetles as bioindicators. Agric Ecosyst Environ 74:357-372

Clough Y, Kruess A, Kleijn D, Tscharntke T (2005) Spider diversity in cereal fields: comparing factors at local, landscape and regional scales. J Biogeogr 32:2007-2014. https://doi.org/10.1111/j.1365-2699. 2005.01367.x

Cole LJ, Mccracken DI, Dennis P et al (2002) Relationships between agricultural management and ecological groups of ground beetles (Coleoptera: Carabidae) on Scottish farmland. Agric For Entomol 93:323-336

Collins KL, Boatman ND, Wilcox A et al (2002) Influence of beetle banks on cereal aphid predation in winter wheat. Agric Ecosyst Environ 93:337-350

Dennis P, Wratten SD (1991) Field manipulation of populations of individual staphylinid species in cereals and their impact on aphid populations. Ecol Entomol 16:17-24. https://doi.org/10.1111/j.1365-2311. 1991.tb00188.x

Dormann CF, McPherson JM, Araújo B M, et al (2007) Methods to account for spatial autocorrelation in the analysis of species distributional data: a review. Ecography 30:609-628. https://doi.org/10.1111/j. 2007.0906-7590.05171.x

Duflot R, Ernoult A, Aviron S et al (2017) Relative effects of landscape composition and configuration on multi-habitat gamma diversity in agricultural landscapes. Agric Ecosyst Environ 241:62-69. https:// doi.org/10.1016/j.agee.2017.02.035

Eyre MD, Luff ML, Leifert C (2013) Crop, field boundary, productivity and disturbance influences on ground beetles (Coleoptera, Carabidae) in the agroecosystem. Agric Ecosyst Environ 165:60-67. https://doi.org/10.1016/j.agee.2012.12.009

Fahrig L, Baudry J, Brotons L et al (2011) Functional landscape heterogeneity and animal biodiversity in agricultural landscapes. Ecol Lett 14:101-112. https://doi.org/10.1111/j.1461-0248.2010.01559.x

Frank T, Reichhart B (2004) Staphylinidae and Carabidae overwintering in wheat and sown wildflower areas of different age. Bull Entomol Res 94:209-217. https://doi.org/10.1079/ber2004301

Frank T, Aeschbacher S, Zaller JG (2012) Habitat age affects beetle diversity in wildflower areas. Agric Ecosyst Environ 152:21-26. https://doi.org/10.1016/j.agee.2012.01.027

Freude H, Harde KW, Lohse GA (1964-83) Die Käfer Mitteleuropas. Bände 1-11. Goecke \& Evers, Krefeld 
Geiger F, Wäckers FL, Bianchi FJJA (2009) Hibernation of predatory arthropods in semi-natural habitats. Biocontrol 54:529-535. https://doi.org/10.1007/s10526-008-9206-5

Geiser R (1998) Rote Liste der Käfer (Coleoptera). In: Binot M, Bless R, Boye P, et al. (eds) Rote Liste gefährdeter Tiere Deutschlands. - Schriftenreihe für Landschaftspflege und Naturschutz. Bonn-Bad Godesberg, pp 178-179

Gobbi M, Barragán Á, Brambilla M et al (2018) Hand searching versus pitfall trapping: how to assess biodiversity of ground beetles (Coleoptera: Carabidae) in high altitude equatorial Andes? J Insect Conserv 22:533-543. https://doi.org/10.1007/s10841-018-0082-8

Görn S, Fischer K (2011) Niedermoore Nordostdeutschlands bewerten: Vorschlag für ein faunistisches Bewertungsverfahren. Naturschutz Landschaftsplan 43:211-217

Haaland C, Naisbit RE, Bersier LF (2011) Sown wildflower strips for insect conservation: A review. Insect Conserv Divers 4:60-80. https://doi.org/10.1111/j.1752-4598.2010.00098.x

Hanson HI, Palmu E, Birkhofer K et al (2016) Agricultural land use determines the trait composition of ground beetle communities. PLoS One 11:1-13. https://doi.org/10.1371/journal.pone.0146329

Hoffmann H, Michalik P, Görn S, Fischer K (2016) Effects of fen management and habitat parameters on staphylinid beetle (Coleoptera: Staphylinidae) assemblages in north-eastern Germany. J Insect Conserv 20:129-139. https://doi.org/10.1007/s10841-016-9847-0

Holland JM, Luff ML (2000) The effects of agricultural practices on Carabidae in temperate agroecosystems. Integr Pest Manag Rev 5:109-129. https://doi.org/10.1023/A:1009619309424

Holland JM, Douma JC, Crowley L et al (2017) Semi-natural habitats support biological control, pollination and soil conservation in Europe. A review. Agron Sustain Dev 37:31. https://doi.org/10.1007/ s13593-017-0434-X

Homburg K, Homburg N, Schäfer F et al (2014) Carabids. org - a dynamic online database of ground beetle species traits (Coleoptera, Carabidae). Insect Conserv Divers 7:195-205. https://doi.org/10.1111/icad. 12045

Jost L (2006) Entropy and diversity. Oikos 113:363-375.

Kleijn D, Rundlöf M, Scheper J et al (2011) Does conservation on farmland contribute to halting the biodiversity decline? Trends Ecol Evol 26:474-481. https://doi.org/10.1016/j.tree.2011.05.009

Knapp M, Řzáč M (2015) Even the smallest son-crop habitat islands could be beneficial: distribution of carabid beetles and spiders in agricultural landscape. PLoS One 1-20.

Kosewska A, Skalski T, Nietupski M (2014) Effect of conventional and non-inversion tillage systems on the abundance and some life history traits of carabid beetles (Coleoptera: Carabidae) in winter triticale fields. Eur J Entomol 111:669-676. https://doi.org/10.14411/eje.2014.078

Kovács-Hostyánszki A, Korösi Á, Orci KM et al (2011) Set-aside promotes insect and plant diversity in a Central European country. Agric Ecosyst Environ 141:296-301. https://doi.org/10.1016/j.agee.2011. 03.004

Kromp B (1999) Carabid beetles in sustainable agriculture: a review on pest control efficacy, cultivation impacts and enhancement. Agric Ecosyst Environ 74:187-228. https://doi.org/10.1016/b978-0-44450019-9.50014-5

Lange M, Türke M, Pašalić E et al (2014) Effects of forest management on ground-dwelling beetles (Coleoptera; Carabidae, Staphylinidae) in Central Europe are mainly mediated by changes in forest structure. For Ecol Manage 329:166-176. https://doi.org/10.1016/j.foreco.2014.06.012

Lethmayer C, Nentwig W, Frank T (1997) Effects of weed strips on the occurrence of noxious coleopteran (Nitidulidae, Chrysomelidae, Curculionidae). J Plant Dis Prot 104:75-92

Longley M, Cilgi T, Jepson PC, Sotherton NW (1997) Measurements of pesticide spray drift deposition into field boundaries and hedgerows: 1. summer applications. Environ Toxicol Chem 16:165-172.

Marrec R, Caro G, Miguet P et al (2017) Spatiotemporal dynamics of the agricultural landscape mosaic drives distribution and abundance of dominant carabid beetles. Landsc Ecol 32:2383-2398. https://doi. org/10.1007/s10980-017-0576-X

Marshall EJ, Moonen AC (2002) Field margins in northern Europe: Their functions and interactions with agriculture. Agric Ecosyst Environ 89:5-21

Martin EA, Dainese M, Clough Y et al (2019) The interplay of landscape composition and configuration: new pathways to manage functional biodiversity and agroecosystem services across Europe. Ecol Lett 22:1083-1094. https://doi.org/10.1111/ele.13265

Meek B, Loxton D, Sparks T et al (2002) The effect of arable field margin composition on invertebrate biodiversity. Biol Conserv 106:259-271. https://doi.org/10.1016/S0006-3207(01)00252-X

Oksanen J, Blanchet FG, Friendly M et al (2020) vegan: Community Ecology Package. R package version 2.5-7

Paradis E, Schliep K (2019) Aape 5.0: an environment for modern phylogenetics and evolutionary analyses. in R Bioinformatics 35:526-528. https://doi.org/10.1093/bioinformatics/bty633 
Perkins AJ, Maggs HE, Watson A, Wilson JD (2011) Adaptive management and targeting of agri-environment schemes does benefit biodiversity: a case study of the corn bunting Emberiza calandra. J Appl Ecol 48:514-522. https://doi.org/10.1111/j.1365-2664.2011.01958.x

Pfiffner L, Luka H (2000) Overwintering of arthropods in soils of arable fields and adjacent semi-natural habitats. Agric Ecosyst Environ 78:215-222

Rainio J, Niemela J (2003) Ground beetles (Coleoptera: Carabidae) as bioindicators. Biodivers Conserv 12:487-506.

Ricotta C, Moretti M (2011) CWM and Rao's quadratic diversity: a unified framework for functional ecology. Oecologia 167:181-188. https://doi.org/10.1007/s00442-011-1965-5

Schirmel J, Thiele J, Entling MH, Buchholz S (2016) Trait composition and functional diversity of spiders and carabids in linear landscape elements. Agric Ecosyst Environ 235:318-328. https://doi.org/ 10.1016/j.agee.2016.10.028

Schneider G, Krauss J, Boetzl FA et al (2016) Spillover from adjacent crop and forest habitats shapes carabid beetle assemblages in fragmented semi-natural grasslands. Oecologia 182:1141-1150. https://doi. org/10.1007/s00442-016-3710-6

Seibold S, Gossner MM, Simons NK et al (2019) Arthropod decline in grasslands and forests is associated with landscape-level drivers. Nature 574:671-674. https://doi.org/10.1038/s41586-019-1684-3

Sirami C, Gross N, Baillod AB et al (2019) Increasing crop heterogeneity enhances multitrophic diversity across agricultural regions. Proc Natl Acad Sci U S A 116:16442-16447. https://doi.org/10.1073/pnas. 1906419116

Statistisches Landesamt Rheinland-Pfalz (2018) Verbandsgemeinde Maifeld - Flächennutzung. http://infot hek.statistik.rlp.de. Accessed 4 Jun 2020

Thomas CFG, Brown NJ, Kendall DA (2006) Carabid movement and vegetation density: Implications for interpreting pitfall trap data from split-field trials. Agric Ecosyst Environ 113:51-61. https://doi.org/ 10.1016/j.agee.2005.08.033

Thomas MB, Wratten SD, Sotherton NW (1991) Creation of "island"' habitats in farmland to manipulate populations of beneficial arthropods: predator densities and emigration”. J Appl Ecol 28:906-917. https://doi.org/10.2307/2404216

Tscharntke T, Klein AM, Kruess A et al (2005) Landscape perspectives on agricultural intensification and biodiversity - ecosystem service management. Ecol Lett 8:857-874. https://doi.org/10.1111/j.14610248.2005.00782.x

Tscharntke T, Clough Y, Wanger TC et al (2012) Global food security, biodiversity conservation and the future of agricultural intensification. Biol Conserv 151:53-59.

Van Buskirk J, Willi Y (2004) Enhancement of farmland biodiversity within set-aside land. Conserv Biol 987-994.

Weibull A-C, Östman Ö (2003) Species composition in agroecosystems: The effect of landscape, habitat, and farm management. Basic Appl Ecol 4:349-361. https://doi.org/10.1078/1439-1791-00173

Winqvist C, Bengtsson J, Öckinger E et al (2014) Species' traits influence ground beetle responses to farm and landscape level agricultural intensification in Europe. J Insect Conserv 18:837-846. https://doi. org/10.1007/s10841-014-9690-0

Woodcock BA, Redhead J, Vanbergen AJ et al (2010) Impact of habitat type and landscape structure on biomass, species richness and functional diversity of ground beetles. Agric Ecosyst Environ 139:181-186. https://doi.org/10.1016/j.agee.2010.07.018

Publisher's Note Springer Nature remains neutral with regard to jurisdictional claims in published maps and institutional affiliations. 